\title{
The effects of an interpolated ITI stimulus on classical conditioning of the nictitating membrane response of the rabbit'
}

\author{
NEIL M. KETTLEWELL AND JAMES D. PAPSDORF \\ UNIVERSITY OF MICHIGAN
}

Fourteen rabbits underwent classical conditioning of the nictitating membrane response while restrained in a darkened experimental enclosure. The experimental Ss, subjected to a $10 \mathrm{sec}$ period of illumination of the experimental enclosure occurring $40 \mathrm{sec}$ after UCS offset and $40 \mathrm{sec}$ prior to CS onset, conditioned at a significantly slower rate.

Pavlov's (1927) investigations of external inhibition phenomena, i.e., decrements in the amplitude of salivary CRs in dogs upon presentation of novel "nongustatory" stimuli, were generally concerned with the effects of such stimuli delivered on isolated test trials and presented just prior to or during CS onset. The concern of the present investigation was to determine whether an extraneous stimulus presented more temporally removed from CS onset and delivered after every conditioning trial would have any effect on the rate of acquisition or asymptotic performance level of the classically conditioned nictitating membrane response of the rabbit.

Method

The apparatus and procedure employed in classical conditioning of the nictitating membrane response has been described in detail by Gormezano (1967). Briefly, 14 albino rabbits, 80-100 days old, were prepared $48 \mathrm{~h}$ prior to conditioning by tying a nylon loop into the nictitating membrane and implanting wound clips into the skin approximately $1 / 2$ in. caudal to the right eye. On the day following preparation, $S$ was placed in a plexiglas restraining box and a head harness, with a photoelectric transducer, mounted on its muzzle. The Ss were then placed in a darkened sound attenuating chamber for a $15 \mathrm{~min}$ habituation period. On each of the subsequent conditioning sessions, given one per day for five days, Ss received $18 \mathrm{CS}-\mathrm{UCS}$ pairings at a fixed intertrial interval of $90 \mathrm{sec}$. The $\mathrm{CS}$, a $93 \mathrm{~dB}, 1000 \mathrm{cps}$ tone, was presented for 1100 msec with the UCS, a $3.0 \mathrm{~mA}, 60 \mathrm{cps}$ shock, overlapping the last $100 \mathrm{msec}$ of CS presentation. The Dark $(N=7)$ and Light Disrupt $(N=7)$ groups were run under identical conditions except that Ss in the latter group were subjected to a $10 \mathrm{sec}$ period of illumination of two $1-1 / 2 \mathrm{~V}$ bulbs, located directly in front of and above S's head. Light onset occurred approximately $40 \mathrm{sec}$ after UCS offset and terminated approximately $40 \mathrm{sec}$ prior to $\mathrm{CS}$ onset. CRs were defined as a 1 $\mathrm{mm}$ or more deflection of the Offner recording pen occurring $50 \mathrm{msec}$ after $\mathrm{CS}$ onset and up to the moment of UCS presentation.

\section{Resulis and Discussion}

The mean percentage of CRs across blocks of 18 trials for each of the two groups is plotted in Fig. 1. As can be seen in the figure, the Light Dismupt group conditioned at a considerably slower rate than did the Dark group $(F=17.40, d f=4 / 40$; $M S$ error $=765.20$, $\mathrm{p}<.01$ ) with both groups eventually reaching the same asymptote.

The pronounced depression produced by the interpolated intertrial interval stimulus can be presently accounted for by two theoretical positions. The first, Pavlov's (1927) competing response hypothesis, contends that novel stimuli elicit the investigatory reflex and that once this "... investigatory reflex is elicited, the conditioned reflex is consequently inhibited"'(p.46). While cortical desynchronization, a correlate of the investigatory or orienting reflex, usually persists for only $10 \mathrm{sec}$ following termination of a novel stimulus, which would argue against the application of Pavlov's competing response notion to the present results, both the grossness of the EEG recording as an analytical tool and the known dissociation between behavioral arousal and cortical desynchronization make ithazardous to utilize such evidence in evaluating this response

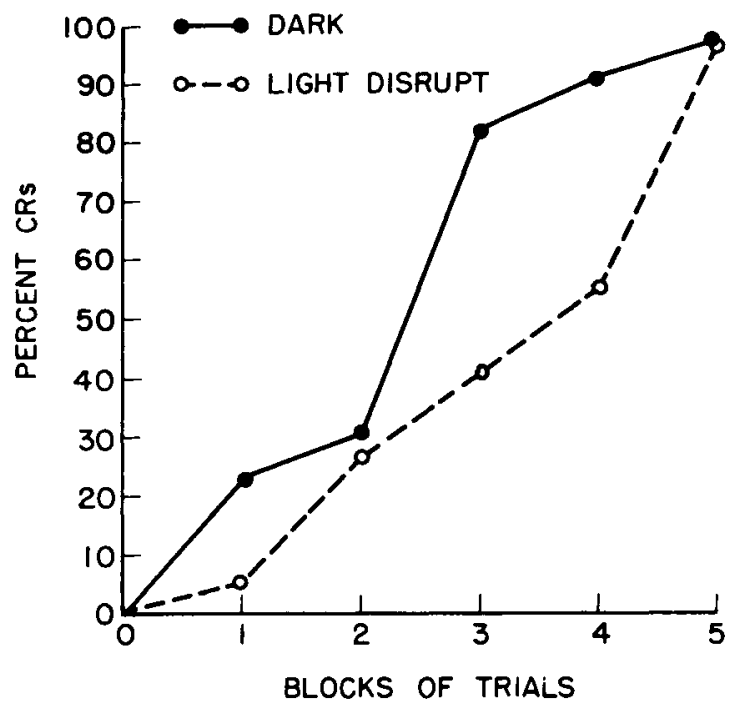

Fig. 1. The percentage CRs for the two experimental groups plotted in 18-trial blocks. 
competition hypothesis. A more adequate demonstration of its validity would consist in showing that interpolated stimuli presented closer to CS onset have more of a depressive effect on conditioning than stimuli more temporally removed. Contrary to this prediction, a recent investigation from the Michigan lab (Papsdorf \& Kettlewell, in preparation) indicates that an extraneous stimulus presented $10 \mathrm{sec}$ prior to $\mathrm{CS}$ onset produces less of a depression on the acquisition rate of the classically conditioned nictitating membrane response than one presented $30 \mathrm{sec}$ prior to CS onset.

The second theoretical position relevant to explaining the effects of the interpolated stimulus would contend that the depression is due to some combination of reactive and generalized conditioned inhibition (Hull, 1943). However, as the Light Disrupt Ss blinked on less than $2 \%$ of the intertrial interval light presentations, it seems unlikely that the consequent inhibition, conditioned and reactive, could have produced the deficit obtained. Finally, the results of the Papsdorf and Kettlewell study cited above would also argue against attributing this depression to reactive inhibition.

Another theoretical approach which could account for the obtained results more adequately would assume that the reaction of the animal to the extraneous intertrial interval stimulus disrupts the ongoing consolidation process. Partial support for a consolidation process in classical conditioning of the nictitating membrane response resides in the observation of Papsdorf, Snyder, \& Cholewiak (in preparation) that injections of strychnine sulphate at the end of each conditioning session facilitate, given certain conditions, response acquisition. Finally, the observation that interpolated stimuli presented $10 \mathrm{sec}$ prior to CS onset have less of a depressive effect on the rate of response acquisition than do stimuli presented $30 \mathrm{sec}$ prior to CS onset (Papsdorf \& Kettlewell, 1967) provides additional support for this position, since it would predict that fewer traces have consolidated shortly after CS-UCS presentation than later in the intertrial interval.

Ready signals have been generally observed to depress classical human eyelid conditioning. Turner (1963), in her investigations of the effect of different ready signal-conditioned stimulus (RS-CS) intervals, obtained a curvilinear relationship with the extent of depression diminishing as the RS-CSinterval decreased from $7 \mathrm{sec}$ to $2 \mathrm{sec}$, and a subsequent increase in the depressive effect of the ready signal with a further increase in proximity of the latter to CS onset. Penneypacker (1967) accounts for Turner's findings concerming the RS-CS gradient by assuming that the ready signal produces three discrete effects: (1) a general inhibitory effect on $\mathrm{CR}$ level due to complex mediational processes; (2) a conditioned readiness which partially offsets the cognitive inhibition and conditions maximally with a 2 sec RS-CS interval; (3) an evocation of a transient (approximately $2 \mathrm{sec}$ ) orientation response which competes with CR performance. However if, in contrast to Penneypacker, the depressive effects of ready signals presented more than 2 sec prior to CS onset are attributed to disruption of consolidation occurring in the intertrial interval and if, in agreement with Penneypacker, CS presented less than $2 \mathrm{sec}$ after a ready signal are presumed to be incapable of eliciting CRs due to response competition, then the RS-CS gradient obtained by Turner can be adequately explained without recourse to presumed cognitive inhibition.

\section{References}

GORMEZANO, I. Classical conditioning. In I. B. Sidowski (Ed.), Experimental methods and instrumentation in psychology. New York: McGraw-Hill, 1966.

HULL, C. L. Principles of behavior. New York: Appleton-CenturyCrofts, 1943.

PAPSDORF, J. D., \& KETTLEWELL, N. M. The effects of different interpolated ITI stimulus-conditioned stimulus intervals on acquisition of the classically conditioned nictitating membrane response of the rabbit. Manuscript in preparation.

PAPSDORF, J. D., SNYDER, RITA E., \& CHOLEWAK, R. W. Interaction effects of strychnine sulphate and the post-conditioning environment on classical aversive conditioning in the rabbit. Manuscript in preparation.

PAVLOV, I. P. Conditioned reflexes. (Trans. by G. V. Anrep). New York: Dover Press, 1926.

PENNEYPACKER, H. S. External inhibition of the conditioned eyelid reflex. In G. A. Kimble (Ed.), Foundations of conditioning and leaming. New York: Appleton-Century-Crofts, 1967.

TURNER, B. B. The effects of a ready signal upon eyelid conditioning. Unpublished doctoral dissertation, Duke University, 1963.

Note

1. This research was supported in part by grants from the Office of Research Administration, University of Michigan and the National Institutes of Mental Health, NIH MH 12504-01, to James D. Papsdorf. 